\title{
Formas do pensar: aportes metodológicos à filosofia brasileira
}

\author{
Ways of thinking: \\ Methodological contributions to the Brazilian philosophy
}

Lúcio Álvaro Marques

https://orcid.org/0000-0002-7571-0977 - E-mail: lucio.marques@uftm.edu.br

\begin{abstract}
RESUMO
Por que não haveria uma filosofia brasileira? Eis a questão que nos move há tempos e que nos levou à identificação de alguns dos paradigmas abaixo. À medida que meditamos sobre ela, entrevimos novos cenários e perspectivas possíveis à elaboração de alguma resposta para a mesma. Neste momento, não oferecemos uma resposta, apenas elencamos possíveis paradigmas compreensivos acerca da originalidade de uma filosofia brasileira, a saber, uma caracterização das posturas: afirmativa, negativa, historiográfica, literário-filosófica, filosofia universitária, sabedoria primitiva, práxis-libertadora, filosofias das visões de mundo estrangeira, intérpretes do Brasil, metafilosofia, e filosofia das formas de pensamento. Essa caracterização não se encontra em muitos dos autores citados, mas a formulamos tão só como uma pré-compreensão de um trabalho mais amplo que estamos desenvolvendo em torno das metodologias filosóficas brasileiras e, em parte também, latino-americanas, cujo foco será responder à questão inicial. Dois esboços precedentes foram apresentados no IESMA e na UFOP. Cumpre-nos averiguar a coerência e a utilidade desses paradigmas como pretexto à questão "o que é filosofia brasileira"?
\end{abstract}

Palavras-chave: Filosofia brasileira. Originalidade. Metodologias. Formas de pensamento.

\begin{abstract}
Why there wouldn't be a Brazilian philosophy? Here is the question that has motivated us for a long time and led us to the identification of some paradigms below. As we have meditated
\end{abstract}


about it, we have glimpsed new scenarios and perspectives that are possible in the elaboration of some answer to it. At this moment, we don't offer an answer. We only list possible paradigms that are understanding about the originality of a Brazilian philosophy, as follows, a characterizing of postures: affirmative, negative, historiographical, literary and philosophical, university philosophy, primitive knowledge, libertarian praxis, philosophies of foreign ways of thinking, interpreters of Brazil, metaphilosophy and philosophy of the ways of thinking. This characterizing is not found in most authors that were mentioned, but we formulated it as a pre-understanding of a broader work that we are developing around the Brazilian philosophical methodologies and, partly, also Latin American, whose focus will be to respond the initial question. Two precedent proposals were presented at the IESMA and UFOP. Our task is to investigate the coherence and utility of these paradigms as a pretext to the question: what is Brazilian philosophy?

Keywords: Brazilian philosophy. Originality. Methodologies. Ways of thinking.

Entre afirmar ou negar a existência de uma filosofia brasileira, há diversas possibilidades: discutir sua existência é possível apenas filosoficamente, diria Aristóteles. Faremos um decálogo de paradigmas com possíveis abordagens acerca da originalidade de uma filosofia brasileira. Não cremos a igual produtividade de todos, por isso tão só os elencamos e esboçamos indícios analíticos, pois estamos desenvolvendo-os de forma mais sistemática para algum momento futuro. No entanto, estes são paradigmas possíveis e, em grande parte, legítimos para pensar a questão da originalidade em filosofia. Cabe-nos, neste momento, ampliar as fontes dessas análises e tatear os indícios de originalidade filosófica e quiçá, futuramente, formular critérios relativos aos usos e modos do fazer filosófico, enquanto exercício de autocompreensão e diálogo intercultural latitudinal (sul-sul) e longitudinal (sul-norte). Afinal, o que significa dizer que somos estudiosos de filosofia? Somos meros eruditos extemporâneos ou nosso fazer tem significação mesmo no tempo em que a economia asfixia tudo quanto não for rentável?

Leopoldo Zea inaugurou um paradigma digno de nota pela originalidade de sua coragem e assertividade de sua proposição, porém não parece uma postura desprovida de pressupostos e isenta de considerações. A filosofia americana como filosofia sem mais soa como uma resposta um tanto cômoda e generalista, porque certo é que todo ser humano, independente de tempo e lugar, pensa, visto ser um homo sapiens, porém o mero pensar, enquanto condição humana não caracteriza por si só o ato filosófico. Nesse sentido, seria uma resposta cômoda e generalista. Zea não se restringe à afirmação genérica, porém ela se evidencia no título da obra citada. Filosofar demanda uma posição não apenas genérica e conformista, mas uma decisão intencionada de abordar, analisar e tematizar a realidade a partir de determinados pressupostos teóricos. Eles os situou na afirmação da condição humana e na dimensão ativa do pensar em relação à realidade (ZEA, 1989, p. 116). Quanto à humanidade, por absurdo que pareça, a América Latina sempre teve sua condição humana negada ou menosprezada aos olhos do pensamento centralista (europeu e norte-americano) durante séculos. Desde o Breve Pastorale officium de Paulo III (1537) e o debate de Valladolid entre Las Casas e Sepúlveda (1550) até a interpretação de Roque Zimmermann em América Latina: o não-ser (1987), a humanidade 
latino-americana foi tematizada e/ou negada sob diversas formas. O pensar inclui uma dimensão ativa capaz de se propor diante da realidade estabelecida como viés de ação no mundo e outra dimensão capaz de nos tornar conscientes de "nossa condição de subordinação, mas também a forma de superar esta condição" (ZEA, 1989, p. 118). Enquanto ação no mundo, o pensar forma consciências capazes de superar a subordinação e formular vieses de ação crítica ao real. A subordinação da consciência latino-americana resulta da naturalização dessa condição durante séculos como se fosse uma necessidade e em virtude do processo colonialista nas formas material, simbólica, estrutural e espiritual. Resultando, assim, na negação da própria humanidade presente nestas plagas. Por isso, Zea insiste em se colocar a favor de uma filosofia latino-americana que seja "filosofia sem mais do humano e para o humano onde quer que este se encontre" (1989, p. 119). Sua proposta não é desprovida de honestidade, visto que o não-ser se instituiu entre nós não como realidade metafísica, mas como resultado da negação direta da humanidade neste continente, por isso afirma (1989, p. 117):

Para concluir, a la pregunta sobre la posibilidad de una filosofía americana, de una filosofía de nuestra América, sólo cabe una respuesta, no sólo es posible sino que lo ha sido o lo es, independientemente de la forma que la misma haya tomado, independientemente de su autenticidad o inautenticidad. En esta filosofía, en la de lo que ha sido posible realizar, está la base de lo que se quiere seguir realizando.

Afirmar a filosofia independente de sua forma soa ingênuo frente à situação que o debate atingiu em nossos dias. Ademais, um pensar independente de autenticidade ou inautenticidade não interessa à filosofia, pois a consciência inautêntica foi a racionalidade que conduziu historicamente a um pensar subordinado à consciência estrangeira e incapaz de tomar consciência e agir criticamente. Nesse sentido, somente interessa uma filosofia autêntica que conduza tanto à reflexão sobre a condição humana quanto à capacidade de agir frente à realidade. Seria anacrônico cobrar de Zea um discurso decolonial, mas não podemos nos permitir a mera repetição servil do pensar alheio. Precisamos sair de nossa menoridade reflexiva e instituir um pensar autenticamente latino-americano e decolonial. Por isso, não cremos a mera afirmação do pensar como uma postura suficiente para uma filosofia sem mais. Filosofar não se reduz à capacidade de pensar inata no homo sapiens, mas exige reflexão autêntica e capacidade de ação crítica na realidade.

A Crítica da razão tupiniquim de Roberto Gomes talvez soe como um manifesto contra a assertividade de Leopoldo Zea. $\mathrm{O}$ autor catarinense formulou uma crítica honesta à ausência de compromisso entre a filosofia e a realidade nacional, quase no mesmo teor que a recente análise de Ronie Silveira (2016). Roberto Gomes critica frontalmente a forma ingênua que conduz à confusão da filosofia entre-nós com filosofia nossa (2001, p. 57). O fato de haver obras filosóficas brasileiras não é suficiente para caracterizar uma tal filosofia, porque o apego à MãeEuropa inviabiliza a capacidade de um pensar original, e mais: esse apego "dispensa-nos de pensar", reduzindo-nos à patética repetição do pensar alheio. O resultado é, justamente, "o que faz com que entre-nós a Razão Dependente e a Ornamental se tenham transformado em Razão Afirmativa do vigente" (GOMES, 2001, p. 63). Nossa condecoração filosófica não ultrapassou as claves da dependência e do adorno cultural, pelo menos até o momento em que Gomes formulou sua crítica (1977). As razões da dependência talvez se refiram a algo mais que o explicitado pelo autor. Cremos que a dependência e o ornamento devam-se, de alguma forma, à pró- 
pria arquitetura acadêmica brasileira, exatamente na clave crítica apresentada por Paulo Arantes (1994) comentando a declaração de Oswaldo Porchat: "a filosofia é antes de tudo explicação e discurso": argumento que entendemos como a redução da filosofia à exegese e ao comentário de obras estrangeiras. Tal apego não nos permitiria passar além da mera tarefa acadêmica de analisar e comentar, não obstante seus méritos. Donde decorre a confusão entre filosofia entre-nós como filosofia nossa. Exatamente no sentido expresso por Gomes (2001, p. 67):

Confundir autores entre-nós com Filosofia nossa; buscar dissolver a oposição entre o isolamento e o alheamento; negar que tenhamos capacidade de pensar por conta própria; projetar nossa falta de pensamento numa possível insuficiência da nossa língua. Nada disso diz respeito à essência possível de um pensar brasileiro: são, ao contrário, tantos outros sinais de nosso esquecimento.

A capacidade reflexiva não se manifesta pela mera existência de obras filosóficas escritas no Brasil, mas pela inserção do Brasil como sujeito e objeto das discussões. Não somos carentes de reflexividade, mas o fato de fazer exegese e comentário de obras estrangeiras torna-nos eruditos na cultura externa, mas nem por isso filósofos brasileiros. Não temos carência de linguagem nem necessidade de exotismo temático. Temos que nos pensar para superar a racionalidade ornamental e dependente, senão pagaremos o preço do autoesquecimento. Uma filosofia brasileira não se confunde com os ismos nem com as novidades do pensar estrangeiro. A razão dependente formou não apenas a economia, mas uma racionalidade colonizada, uma erudição estrangeirada que desconhece a própria realidade, uma crença na cultura dos outros e um descrédito quanto à própria cultura com a redução da cultura nacional à escória da indústria cultural, um esquecimento de si em vistas da centralidade alheia. "Em consequência, o intelectual tupiniquim vive num estado de dissociação: voltado para fora e de fora esperando reconhecimento" (GOMES, 2001, p. 73). Deixamos que os véus do autoesquecimento e do escondimento se sobreponham à nossa realidade e queremos pensar com, a partir de e a realidade alheia. Donde se segue que "o pensamento pode existir entre-nós sob a condição de não pensar. Ou: de não existir" (GOMES, 2001, p. 80). E, ao lado de Gomes, pode-se considerar as razões postas por Silveira como possíveis causas da falta de originalidade: a ausência de liberdade e democracia, a pobreza e a desigualdade social e o afã da interlocução internacional ao preço do esquecimento e do abandono do assunto nacional (2016, p. 274-5). Concordamos com Silveira ao detectar a necessidade de incorporar o Brasil na agenda internacional da filosofia (2016, p. 277), mas não serão os estrangeiros que o farão, somos nós. E, no passo contrário do que pensa esse autor: "portanto, não apenas há filosofia brasileira como ela é brasileiríssima ao ser praticada de costas para o Brasil", cremos o contrário. Há muitos autores fazendo esse debate, desde L. W. Vita e S. Romero a P. Margutti e I. Domingues, por exemplo. Não cabe só negar a filosofia brasileira. Precisamos pensar brasileiramente.

A historiografia do pensamento brasileiro não data de ontem. Temos uma série de obras e obras muito sérias que se dedicaram não apenas à caracterização das correntes de pensamento quanto à periodização. Recordemos alguns autores apenas como exemplos: S. Romero, Luís W. Vita, A. Paim, Jorge Jaime, Cruz Costa, M. Nobre e J. M. Rego, Antônio J. Severino, Luís A. Cerqueira, W. B. Redmond, Palmira Almeida, R. Vainfas, P. Margutti, entre outros que merecem igual consideração. Quanto às histórias da filosofia brasileira, há várias considerações a serem feitas, porém há que se lembrar o inesquecível mérito que cada uma dessas histórias aporta à 
memória da cultura brasileira. A existência de lacunas atesta apenas que há muito ainda por fazer, ou melhor, que talvez estejamos no início desse caminho e que, portanto, todos os esforços são bem-vindos em vistas de, em algum tempo, constituirmos um padrão compreensivo mais amplo.

A primeira consideração, o minimalismo e/ou a megalomania historiográfica. Há historiadores que consideram apenas os grandes vultos culturais dignos de consideração. De onde se segue que teríamos uma história do pensamento minimalista em que pouquíssimos nomes mereceriam atenção e estudo, ou seja, a atenção estaria centrada nos raros autores que impactaram de alguma forma a história do pensamento. Comparando a história filosófica ao universo científico, não tivemos "nenhum prêmio Nobel", mas tivemos um Santos Dumont e Osvaldo Cruz que se destacaram por suas criações. Nesse sentido, teríamos poucos nomes a mencionar. A tentação megalomaníaca seria crer, por exemplo, que todos os autores citados por Jorge Jaime são "filósofos". Não obstante, ele prestou enorme serviço ao catalogar autores antes de caírem no olvido e na falta de fontes.

A segunda, o desinteresse sistemático pela história do pensamento pré-colonial, colonial e pós-colonial: a compreensão da história do pensamento de um povo não se faz através da supressão de qualquer período de sua história. Não obstante a enorme mudança operada pela invasão colonial, ela precisa ser entendida não como o tempo zero da história dos povos brasileiros, mas como um acontecimento dentro de uma história dos povos originários, cujos remanescentes distantes ainda permanecem esquecidos e espoliados em seus territórios e direitos sociais.

A terceira, a carência de estudos dos três períodos resulta em avaliações parciais da história brasileira. O período colonial, por exemplo, carece sistematicamente de estudo em muitas frentes: linguístico, antropológico, histórico, econômico, etc., porque a história dos colégios coIoniais sequer foi elaborada, como recorda S. Leite. O que nos impede de compreender de forma mais ampla e coerente o sentido do ensino que nos precedeu, cujo resultado será sempre uma avaliação parcial do ensino na história brasileira.

A quarta, a limitação inerente a muitas dessas pesquisas, o que revela a necessidade de ampliá-las e atualizá-las. Não as criticamos, apenas carecem de ampliação. Apenas de forma exemplar, recorde-se a ausência quase completa de autores coloniais brasileiros na obra de W. B. Redmond, Bibliography of the Philosophy in the Iberian Colonies of America (1972). A identificação de qualquer dos autores presentes no Catalogus Eborensis (Marques, 2018) carece de referência no Dicionário de autores no Brasil colonial de Palmira A. R. Almeida (2010) e ausência de verbetes sobre universidade, colégios, ensino e professores no Dicionário do Brasil colonial (2000).

A quinta, a historiografia seja convertida em fonte de pesquisa e verticalização dos estudos filosóficos. Apenas a título de exemplo, veja-se Desenvolvimento, cultura, ética: as ideias filosóficas de Mario Vieira de Mello (2015) e Nísia Floresta, uma brasileira desconhecida (2019) de Paulo Margutti que não se reduziu à elaboração de uma história da filosofia monumental que se encontra em curso, mas que se deteve e verticalizou a análise de obras. Verticalização essencial à compreensão global dos autores e, posteriormente, à elaboração de panoramas historiográficos coesos e coerentes.

A propósito, fazer uma filosofia da literatura seria impossível sem recordar Machado de Assis, Benedito Nunes, Sônia Viegas Andrade, Ricardo Timm de Souza (Metamorfose e extinção, 
2000) e Paulo Margutti, apenas a título inicial. E, por certo, é estúpido pensar os diálogos platônicos, a História das minhas calamidades de Abelardo, o Emílio de Rousseau, O homem revoltado de Albert Camus, Temor e tremor de S. Kierkegaard, o 1984 de G. Orwell, Na colônia penal ou O processo de Kafka, O nome da rosa de Umberto Eco, o Manifesto antropofágico de O. Andrade e inúmeras páginas de F. Nietzsche sem considerar o valor literário dessas obras. Por isso, uma filosofia da literatura constitui um verdadeiro canto da sereia. A proximidade temática e a afinidade retórica iludem o leitor desatento levando, não poucas vezes, a paradoxos e retórica vazia, pois uma filosofia da literatura exige tanto a expertise do filósofo quanto a sutileza do literato, aliadas à capacidade de tornar operativos os conceitos literários para além das obras lidas sem transformar o prazer estético da literatura em lógica argumentativo-conceitual aos moldes da filosofia.

A filosofia da literatura talvez seja, por um lado, o aspecto mais promissor para a originalidade da filosofia brasileira, como o próprio Lima Vaz endossou (1984, p. 23) e, por outro, o exercício mais difícil enquanto perícia teórica e especulativa para não operar abusivamente com os conceitos. O jagunço-filósofo de Guimarães Rosa é um pensador original pelo tour de force linguístico e retórico na travessia do sertão, mas, certamente, desprovido de interesse conceitual à moda dos filósofos. Riobaldo afirma que seu cavalo f'losofou, malgrado a onomatopeia, nem o cavalo nem o próprio Guimarães Rosa estariam filosofando na travessia do sertão. $\mathrm{O}$ interesse estético-literário, certamente, sobrepõe-se a qualquer outro, não obstante o emprego de linguagem e conceitos ditos filosóficos, mas com outra finalidade. O reverso também é igualmente verdadeiro: como não entender O nome da rosa como uma interpretação crítica das relações de poder no interior do sistema de conhecimento medieval? Esses exemplos devem nos encorajar não só à pretensão de fazer filosofia a partir da literatura, mas de pensar sinceramente quão árdua é essa tarefa a quantos a desenvolvem com lucidez e rigor crítico sem violentar nenhuma das partes, como adverte Rocha na Introdução aos contos filosóficos macha$\operatorname{dianos}(2008$, p. 9):

Discutir a "filosofia" de Machado de Assis (ou a "filosofia" de sua obra) conduz a um malentendido; afinal, o exercício do escritor implica uma vocação muito diversa. A obra machadiana ilumina a força da experiência literária: literatura é pensamento em ação: literatura éfilosofia que não para de pensar, pois não se compromete com "verdade" alguma, a não ser com o questionamento da ideia mesma de "verdade".

Rocha destaca a função iconoclasta da literatura e seu descompromisso conceitual, sua veracidade "propriamente ficcional e não filosófica" (ROCHA, 2008, p. 10), enquanto Benedito Nunes advoga a função poético-profética do conceito filosófico e vice-versa (NUNES, 2010, p. 18): "pondo-a em obra, a arte mostra a verdade do ser, torna-a visível ou audível, quebrando a banalidade do cotidiano. [...]. Aí o filósofo faz-se poeta, e o poeta profetiza. Não fosse poeta um homônimo de profeta". A correspondência entre literatura e filosofia pode ser tanto criticada quanto defendida, porém o pensar filosófico-literário ou literário-filosófico constitui-se de um diálogo entre dois universos retórico-discursivos bastante distintos tanto na forma (exercício de estilo e retórica em vista do prazer estético e/ou exercício teórico-demonstrativo via racionalidade conceitual stricto sensu) quanto no conteúdo (construção ficcional-narrativa e/ou argumentação lógico-demonstrativa). Pensa-se tanto literária quanto filosoficamente e, desse ponto à elaboração filosófica da literatura, há um longo e árduo exercício de autocompreensão e diálogo interdisciplinar. 
Sílvio Romero foi tão profícuo em ideias brilhantes quanto em polêmicas e, por isso, igualmente odiado por tantos. Não obstante, capitaneia um filão interpretativo justo, produtivo e crítico. Não poucos autores contemporâneos seguem sua trilha e aportam boas novidades à autocompreensão da filosofia brasileira. Eis suas notas (2001, p. 143):

\begin{abstract}
As academias são poucas e de criação recente. Ainda hoje há muita dificuldade para a aquisição de cultura neste país; os cursos, além de raros, são espalhados a grandes distâncias da maior parte dos Estados. Os livros são caros; a carreira das letras não traz vantagens; a vida intelectual não oferece atrativos; não há editores nem leitores para obras nacionais; por isso quase ninguém escreve, para não ser esmagado pela concorrência estranha.
\end{abstract}

Escrita em 1888, essa análise ainda conserva um grau de veracidade, senão o todo, ao menos em parte: a gênese tardia de instituições universitárias, de cursos superiores e a dispersão geográfica caracterizariam parte de nosso atraso acadêmico. $O$ autor não põe em grande relevo o ensino administrado pela Igreja no período colonial e, segundo a datação oficial, o ensino superior universitário tardaria até a primeira metade do século passado, embora tenhamos pessoalmente bons motivos para discordar (MARQUES, 2018, p. 101-15). O livro ainda parece reservado a objeto de estima e adorno bibliotecário, mas esse cenário sofre, felizmente, a derrocada graças à popularização das edições eletrônicas open access que contrastam abertamente com a escandalosa política editorial de "algumas" editoras tradicionais. A carreira universitária ainda não é sólida, especialmente no cenário atual em que a política do Governo Federal trabalha decidida e abertamente para degradar as condições de existência da universidade pública, tendo-a eleito como principal inimiga. $E$, de tudo isso, o resultado não poderia ser outro (ROMERO, 2001, p. 146): "a nação brasileira não tem pois em rigor uma forma própria, uma individualidade característica, nem política, nem intelectual". A carência política e educacional ainda é nota atualíssima em que, por um lado, o jogo democrático descambou em difamação personalista e fake news e, por outro, o ensino público foi eleito como inimigo da sociedade, graças aos interesses da iniciativa privada no campo do ensino. Somem-se a isso os grilhões da exegese e comentários que conduzem "todas as nossas escolas, numa e noutra esfera não têm feito mais em geral do que glosar, em clave baixa, as ideias tomadas da Europa, às vezes em segunda ou terceira mão" (ROMERO, 2001, p. 146-147). A consequência quase que natural é a reduzida inventividade acadêmica e a incapacidade de produzir por si.

A interpretação de Romero parece, de certa forma, validada por Lima Vaz tanto ao afirmar que não há nenhum interesse entre as teses do ensino colonial e a sociedade em que foram produzidas quanto na consideração quase que estrita do ensino universitário como instância única do conhecimento (VAZ, 1984, p. 20s). Se o tivermos por verdadeiro, o ensino universitário com pós-graduação esperará a segunda metade do século passado para emergir. Nesse sentido, a invenção da pós-graduação caracterizará uma universidade recentíssima sem tradição nem relevo para pensar a vida brasileira (ALMEIDA, 2017). Em consequência, a filosofia brasileira não passaria de um tópico a ser pautado e inventado doravante. Essa filosofia seria um compromisso a devir, uma promessa de realização na recente tradição universitária e um compromisso de justiça com o povo brasileiro (VAZ, 1984, p. 24-5):

O Brasil, é forçoso reconhecê-lo, apresenta hoje uma das sociedades mais dramaticamente injustas entre quantas existem sobre a face da terra. [...] A cultura filosófica e o exercício da reflexão filosófica têm, assim, definido seu lugar social no Brasil de hoje. E é um lugar que ouso apontar como elevação sobre a realidade fragmentária e aparentemente caótica, de onde ela pode ser abrangida em visão sinótica; onde os fins da sociedade 
podem ser pensados e descortinadas as direções de um caminho que seja para ela historicamente viável.

O compromisso filosófico com a justiça e a ética na sociedade brasileira torna-se, crescentemente, central. Não obstante, discorda-se do mesmo autor ao considerar o acesso ao pensar pré-colombiano (VAZ, 1984, p. 18): "filosofia sobre as culturas pré-colombianas ou sobre o que delas resta é possível e, talvez, interessante, mas só a podemos fazer da mesma maneira com que Platão filosofava sobre os mitos da Lídia ou do Egito". Não se trata de culturas míticas, ao contrário, de culturas em sentido amplo e irrestrito e podem ser exemplificadas pelas grandes obras que nos legaram: Popol Vuh, Chilam Balam de Chumayel, Rabinal Achí e as épicas Náhuatl, além dos sítios arquitetônicos, das pinturas rupestres e dos resultados das pesquisas arqueológicas. Por isso, quem quiser acessar uma compreensão menos incongruente dos povos originários, deve-se voltar aos esforços de um saber interdisciplinar - arqueologia, paleontologia, antropologia evolutiva, história, linguística, etc. - em vistas de compreender e reconectar os saberes atuais às culturas dos povos originários, barbarizados pelos ditos civilizados europeus. Urge reencontrar a sabedoria primitiva dos povos originários, sobretudo, em vistas de reconstruir a história deste continente, livre de fantasias eurocêntricas, e minimizar a biopirataria cultural e ambiental que assola os povos e a biodiversidade remanescente das culturas nativas. Acessar as culturas primitivas permite decolonizar os saberes originários frente à ilusão indo-europeia: "la filosofía del Oriente o de Amerindia sería filosofía en sentido amplio; la de Grecia, en sentido estricto" (DUSSEL et al., 2009, p. 19). Somente à medida que decolonizarmos a epistemologia, reconheceremos a originalidade das cosmovisões não-indo-eurocêntricas e reconectaremos os saberes originários à sua história, ou melhor, redescobriremos a ancestralidade cultural dos povos originários. Dussel retoma o lastro histórico dos saberes e filosofias originários (2009, p. 19):

\footnotetext{
Hay entonces filosofías en las grandes culturas de la humanidad, con diferentes estilos y desarrollos, pero todas producen (algunas de manera muy inicial, otras con alta precisión) una estructura categorial conceptual que debe llamarse filosófica. [...] El discurso filosófico no destruye el mito, aunque sí niega aquellos que pierden capacidad de resistir el argumento empírico de dicho discurso. [...] Por otra parte, hay elementos míticos que contaminan también los discursos, aun los de los grandes filósofos.
}

A colonização mental, certamente, é a principal responsável pela ilusão de que há filosofia stricto sensu somente segundo o padrão indo-europeu. Dussel faz notar que as estruturas categoriais conceituais e as relações mítico-filosóficas constituem o arcabouço teórico das grandes culturas, inclusive, a latino-americana. E, nesse sentido, os povos originários desenvolveram suas filosofias, tal como se pode bem compreender na primeira parte da obra El pensamiento filosófico latino-americano (2009, p. 20ss) dedicada às filosofias náhuatl, maya, tojolabal, quechua, mapuche e guarani e seu devir:"de todas maneras se tiene conciencia de que la exposición de las filosofías amerindias deberá desarrollarse mucho en el futuro".

Tal desenvolvimento alia-se, direta e imediatamente, à transdisciplinaridade em busca de reconectar o conhecimento à ancestralidade dos povos originários. Apenas uma epistemologia decolonizada permite um acesso aos registros culturais, antropológicos e arquitetônicos pré-colombianos. A título de exemplo, a descoberta de uma decapitação e sepultamento ritual 
na Lapa do Santo em Santa Luzia (MG) datado de, aproximadamente, nove mil anos antes do presente (STRAUSS, 2015), na cova 26, revela não apenas a existência de pessoas, mas um povoamento com ritos funerários e uma cultura bastante elaborada. Donde se segue que, sem esquecer a brutalidade da invasão colonial, se quisermos reencontrar uma história real sobre os povos que atualmente habitam as Américas, temos que reconectar o conhecimento atual aos conhecimentos possíveis dos povos destruídos pela barbárie moderna europeia através do mergulho no palácio da memória e da história.

\section{VII}

A filosofia da práxis-libertadora constitui a melhor expressão de uma filosofia original latino-americana, salvo engano. Tanto na sua expressão continental, presente na filosofia e teologia da libertação, quanto na sua expressão nacional, na pedagogia da libertação, também comporta uma dimensão internacional. Dois nomes destacam-se nesses cenários: Enrique Dussel e Paulo Freire. Ambos constituíram, cada qual a seu modo, uma filosofia e uma pedagogia da libertação, respectivamente. Uma característica marcante desse paradigma encontra-se na aplicação do materialismo histórico como critério interpretativo mediando a universalidade e a singularidade. O resultado aponta na direção da particularidade da análise, articulada dialeticamente à realidade concreta (o singular) e à abstração teórica (o universal). Esse método não se restringe ao uso que os dois fizeram dele, pois tantos outros também o empregaram de forma igualmente produtiva. Veja-se, por exemplo, como Gerd Bornheim o emprega na interrogação sobre o ponto de convergência entre a filosofia e a realidade nacional (1998, p. 187; 189):

Retomo as categorias de universalidade e singularidade já utilizadas acima, e acrescentoIhes, seguindo Georg Lukács, a de particularidade. [...]. Com outras palavras: através do singular, o universal alcança configurar um particular determinado, concreto. E pelo universal, o singular abandona o seu confinamento para instituir um particular no qual se pode ler também o universal. [...] Mas o contrário revela-se (des) igualmente válido: a Filosofia também pode impor-se à realidade nacional através de suas exigências específicas, a começar justamente pelo exercício da racionalidade que a caracteriza: pela práxis da crítica.

A práxis crítica ou práxis-libertadora constitui o princípio hermenêutico cuja solidez mostrou-se, nas últimas décadas, um dos mais produtivos tanto na interpretação quanto na proposição de ações interventivas na realidade. A filosofia e a teologia da libertação propiciaram aportes teóricos de grande alcance na análise das desigualdades e injustiças estruturais, bem como críticas aos modelos ditatoriais de governo tão frequentes na segunda metade do século passado e que agora parecem voltar à carga. A pedagogia da libertação centrou-se na constituição de processos educacionais capazes de superar a estaticidade da transmissão de conhecimento em direção à conscientização dos sujeitos do conhecimento ao longo do processo de construção do conhecimento. Tanto a teologia da libertação quanto a pedagogia tiveram e têm seus algozes: à teologia couberam as críticas de J. Ratzinger e à pedagogia, o ódio conservador dos recentes ministros da educação. O que, por sua vez, atesta a coesão e produtividade de ambas.

Para além do universo da própria teologia, seu arcabouço teórico permitiu e ainda permite uma compreensão do campo econômico à luz dos princípios da libertação: esse trabalho foi levado à frente tanto por Franz Hinkelammert quanto Jung Mo Sung, entre outros. A grande diferença presente na epistemologia da práxis-libertadora encontra-se no ponto de partida interpretativo, ou seja, no método aplicado: a realidade concreta passa a ser interpretada à luz de 
conceitos e categorias universais, lançando luz à compreensão da particularidade de cada realidade em questão. A teologia, a filosofia, a pedagogia e a economia, entre outros, beneficiaram-se dessa capacidade interpretativa e, não poucas vezes, intervieram produtivamente na constituição de uma nova compreensão social e histórica da realidade latino-americana. Por fim, outra dimensão fartamente beneficiada pela aplicação, direta ou indireta, desse método é a ética ecológica, maravilhosamente exemplificada por Leonardo Boff que não apenas ampliou os debates sobre cidadania ecológica quanto chamou a atenção para a corresponsabilidade e urgência de elaborarmos uma ética planetária capaz de pensar todas as formas de vida integradas dinamicamente.

\section{VIII}

A legislação antiescravista de 1831 visava tornar o Brasil um país para inglês ver, isto é, era um prestar contas à monarquia inglesa, porém cumpre notar que nosso país sempre se pensou para os olhos alheios. Vivemos um voyeurismo cultural desde a patética Carta de Pero Vaz de Caminha, passando por tantos relatos de religiosos lusitanos e estrangeiros (J. Léry, A. Thévet, N. D. Villegagnon, etc.), de viajantes (A. Saint-Hilaire, H. Staden e tantos outros reunidos na obra de Jean M. C. França, A construção do Brasil na literatura de viagem dos séculos xvi, xvii e xviii, 2012), além de naturalistas e letrados como Le Brésil de Montaigne, organizado por F. Lestringant (2005), J.-B. Débret, Viagem pitoresca e histórica ao Brasil (1834), Charles Darwin, Alexander von Humboldt, etc. Reincidentemente preocupamo-nos com a imagem apresentada aos olhos estrangeiros. Talvez seja por isso que se valoriza tanto o futebol, o carnaval e o corpo da mulher, infeliz e brutalmente apresentados como "produtos nacionais". A consequência desse voyeurismo é notória: por um lado, assimilamos e introjetamos a visão estrangeira como verdade sobre a cultura nacional e, por outro, estamos sempre na corrida patética para nos assimilarmos às culturas estrangeiras. Não as assimilamos, mas adotamos caricaturas e as tomamos por verdade nacional. Os piores exemplos vêm do anglicismo linguístico, o way of life, a música, a dieta e até o hallowenn à medida que esquecemos nosso rico folclore.

O voyeurismo cultural não se limita à exclusão da memória e costumes nacionais. Há outra face mais nefasta: a acadêmica. Não é raro notar como assimilamos os modismos teóricos, inclusive na realização de simpósios em inglês, quando nem sempre há presença estrangeira que justifique uso da língua franca. Óbvio, as políticas de internacionalização são essenciais, mas não temos que nos submeter à caricatura de ingleses tupiniquins. Esse voyeurismo acadêmico não se limita aos modismos teóricos nem ao inglês caricato, mas releva sua pior face à medida que a academia se reduz a produzir comentário e exegeses de teorias que simplesmente não se adaptam à realidade nacional, senão a fortiori. Presos à ilusão de comentar e exumar os autores centrais da grande tradição ocidental, acaba-se apenas por colonizar a própria mente: estuda-se no Brasil ou no exterior e pensa-se como se houvesse nascido na Europa ou na América do Norte. Qualquer pesquisa que não se deixa confrontar pelo chão da realidade nacional permanece como um fino smoking para ser usado na praia. Não serei filisteu da minha própria formação acadêmica, mas não creio ser possível reduzir a filosofia a comentário e exegese, como diz Margutti (2013, p. 14):

Manter os nossos estudantes de filosofia concentrados apenas no conhecimento dos clássicos do pensamento filosófico estrangeiro pode fornecer-lhes uma sólida formação exegética, mas certamente não os tornará mais preparados para enfrentar os desafios da cultura brasileira. 
O estudo rigoroso dos clássicos permanece sempre uma necessidade, mas não só. Necessário se faz superar o voyeurismo cultural que produz meros assimiladores da visão de mundo e também o voyeurismo acadêmico que simplesmente repete teorias e modismo independente da possível aderência dessas teorias à realidade nacional. Enfim, superar o voyeurismo acadêmico é condição para não nos reduzirmos à importação teórica. Antes, precisamos de coragem para usar as teorias como instrumentos para compreensão de nossa realidade e não apenas as comentarmos simples e servilmente como dogmas de fé. Nada melhor que uma imagem deleuziana para entendermos a utilidade do estudo dos clássicos sem servilismo acadêmico: é necessário tomar uma teoria e seu autor pelas costas e fazer-lhe um filho, isto é, criar uma nova compreensão autônoma e aderente à realidade nacional. Pois superar formas de voyeurismo cultural e acadêmico constitui o ponto de partida para a emancipação teórica quando se alcança a capacidade de assimilação crítica, análise do real e produção de resposta teórica e/ou práticas cuja significação redefine os rumos da sociedade ou, segundo Gabriele Cornelli (2009, p. 33): o trabalho do historiador da filosofia é "um ofício que alia a arqueologia dos textos à hermenêutica de uma história que é, em suas linhas interpretativas, sempre uma história do presente, isto é, um olhar sobre o passado construído a partir das preocupações éticas e teóricas de hoje".

\section{IX}

Há dois paradigmas distintos cujo esquecimento seria grosseiro, embora a menção seja apenas exemplar por razões distintas: os intérpretes do Brasil e a metafilosofia de Ivan Domingues. Não mencionaria os intérpretes sem uma leitura sincera, dada a extensão e complexidade. Consideremos os três monumentais volumes de Intérpretes do Brasil, coordenados por S. Santiago (2002), J. C. Reis, As identidades do Brasil I e Il (2003 e 2006), A. Botelho e L. M. Schwarz (Orgs.), 29 intérpretes e um país (2009), G. Axt e F. Schüler (orgs.), Intérpretes do Brasil (2011), F. H. Cardoso, Pensadores que inventaram o Brasil (2013) e L. B. Pericás e L. Secco (Orgs.), Intérpretes do Brasil (2014). Obras de alta relevância para uma justa compreensão da realidade brasileira não só na demarcação epistêmica em que foram escritas. São obras que aguardam sinceras e potentes leituras e corajosas interpretações filosóficas capazes de tornar produtivos os conceitos de dezenas de pensadores da melhor estirpe para todos os campos teóricos, inclusive a filosofia.

A metafilosofia elaborada por Ivan Domingues em Filosofia no Brasil (2017) diz por si só para que veio: uma obra que nasceu como passagem obrigatória a quem se dedica à filosofia brasileira. Dispensa comentários, dado o número de resenhas e profícuos debates que suscita, além de um número considerável de possibilidades interpretativas em áreas afins. Por isso, retomar sua análise seria simplesmente oneroso nesse momento, dada a extensão e originalidade de um livro que nasceu clássico.

\section{$\mathrm{X}$}

Finalmente, se ainda há algo a dizer, que o façamos, não obstante seja necessário recordar que o elenco de paradigmas não é exaustivo e cada um comporta tanto aspectos positivos quanto negativos, isto é, aspectos mais ou menos produtivos para aproximações da questão relativa à originalidade da filosofia brasileira. Torpe seria acusar a improdutividade de qualquer paradigma como um todo e também seu contrário. Existem aspectos atávicos e comprometedores em todos (ou quase todos) esses paradigmas. Pensar a originalidade de uma fi- 
losofia não significa encontrar uma receita, criticar diagnósticos nem fazer prognósticos. Trata-se muito mais de tatear as formas possíveis ao pensamento que o torne capaz de entender a operacionalidade e efetividade de um jogo conceitual suficientemente amplo, flexível e veraz adaptável à análise cogente de uma realidade.

A África não tinha história até o século passado, como destacamos a partir de $\mathrm{H}$. Wesseling (MARQUES, 2018, p. 30), mas quais são as razões dessa ausência de história? A história da colonização africana não é sua história, mas parte da história de conquistadores realizada naquele continente como objeto de domínio e controle externos. A África fez sua história à medida que integrou a história das conquistas dentro de sua pré-pós-história, ou seja, à medida que desconstruiu os mitos fundadores colonialistas e conectou o seu presente ao passado pré-colonial. Da mesma forma, o Brasil não tem história, pois repete continuamente a patética e mal-intencionada fábula do achamento e descoberta como tempo zero de sua história. A consequência é a perpetuação da inconsciência pré-colonial. Repete-se ad nauseam a mitologia de indígenas tabula rasa, bárbaros e pateticamente pró-colonialistas, esquecendo-se justamente a resistência que apresentaram desde que os intrusos degradados seriam deixados entre eles até os martírios do Bispo Sardinha, Roque González e seus companheiros. Não houve assimilação pacífica da colonização, porém insistimos em esquecer tanto a tragédia colonial quanto em "mitificar" a história pré-colonial. Isso não significa que deveríamos esquecer a história colonial, ao contrário, apenas integrando-a ao pré e ao pós-colonial é que reconheceremos a história da Isola de Brazil e seus desdobramentos. Tanto cremos o imperativo apontado por S. Leite (2006: VII, 224) - "a história da cultura escolar colonial ainda não está feita em bases científicas, o que vem a significar que ainda não se estudou nas suas fontes, dentro do ambiente e dos livros que foram veículos dela" - que nos esforçamos por levá-lo a bom termo (MARQUES, 2015; 2018). Nesse sentido, o primeiro ponto que nos parece essencial é construir a história brasilis antes, durante e depois da barbárie colonial. Caso contrário, estaremos sempre a reafirmar a mitologia colonialista. A formulação de uma história brasilis autônoma constituirá o primeiro passo para uma epistemologia decolonial, visto que uma Isola de Brazil tropical já estava presente na cartografia irlandesa do século treze (MARQUES, 2018, p. 34-57). Faz-se necessário criarmos nossa história decolonial e, ao mesmo tempo, ancestral. A segunda dimensão dessa história será tão ampla quanto fundamental, pois somente saberemos quem somos hoje à medida que reconhecermos e integrarmos nossas ancestralidades de povos originários e africanos na história cotidiana. Enquanto ignorarmos nossa ancestralidade, perpetuaremos o parricídio edipiano dos povos originários e africanos. O seu reconhecimento ainda não é tudo, pois seu lugar de fala foi e é historicamente negado. Não ouvimos a "palavra de nossos antepassados", aliás, não é excessivo afirmar que sequer conhecemos os registros humanos dessas culturas tão suficientemente quanto o faríamos com nossos pais. Há centenas de genealogias brasileiras que sempre conduzem à Europa, mas quantas conhecemos que conduzem à África e/ou às florestas tropicais?

Uma dimensão de máxima importância refere-se à destruição acadêmica da ilusão aquisitiva de um smoking teórico para a praia. Há inúmeras teses com excelente exegese e comentários os mais refinados, rigorosamente elaborados, e que não interessam em nada aos leitores europeus ou norte-americanos, tanto por não trabalhar com fontes primárias quanto por serem análises alheias às culturas dominantes. O ponto crítico não se refere à natureza desses trabaIhos acadêmicos, visto que são "necessários à titulação". O problema está em incutirmos a crença de que basta-nos saber comentar um clássico para fazermos filosofia e, com isso, compramos um belo smoking, mas desconhecemos completamente o corpo ao qual certamente não vestirá, porque o transplante de um arcabouço teórico de país a país rarissimamente serve 
a análises verdadeiramente produtivas. Há muitas teorias bem glosadas em dissertações, teses e comentários, mas que (quase) nada significam para a realidade em que estamos. Assim sendo, a condição de reversão dessa ilusão do smoking implica uma mudança metodológica em nossas pesquisas: antes de partirmos do quadro referencial teórico para talvez chegarmos à análise da realidade, deveríamos partir de um conhecimento arguto da realidade a ser analisada e somente, à medida do necessário, recorrermos aos aparatos teóricos para analisá-la. Com isso, estamos dizendo que o foco da metodologia de pesquisa não deveria ser a exegese e o comentário, mas a realidade histórica analisada à luz de elementos teóricos que se mostrassem produtivos. Talvez assim deixaríamos, paulatinamente, de ser consumidores passivos e servis de teorias importadas (abandonaríamos à epistemologia colonizante) para nos tornarmos produtores de análises e aportes teóricos com coesão interna e articulação crítica com a realidade em que vivemos (estabeleceríamos os pressupostos de uma epistemologia decolonial capaz de pensar nossas ancestralidades e aberta a audição da multiplicidade de vozes de nossos antepassados provenientes de povos originários, africanos e/ou europeus: conforme os pressupostos de uma hermenêutica pluritópica). Essa mudança metodológica implica, em primeiro lugar, conhecer muito bem o lugar histórico em que se pesquisa; em segundo, deslocar o centro de forças da pesquisa: passar da história do pensamento à análise do real; em terceiro, assumir o lugar histórico em que vivemos como nossa responsabilidade acadêmica primária e, em quarto, reconhecer de que história somos fruto e pensar a partir dela com o orgulho de saber-se responsável pela própria história. Afinal, para que serve uma cabeça que pensa quando ela própria desconhece onde se encontram seus pés?

\section{Referências}

ALMEIDA, K. A pós-graduação no Brasil. Tese (Doutorado em Educação). Campinas. 213f. Unicamp, 2017.

ARANTES, P. Um departamento francês de ultramar. Rio de Janeiro: Paz e Terra, 1994.

ASSIS, M. Contos 3: Filosofia. Organização e introdução de J. Rocha. Rio de Janeiro: Record, 2008. BORNHEIM, G. A. O idiota e o espírito objetivo. 2. ed. Rio de Janeiro: UAPÊ, 1998.

CORNELLI, G. “Calcular a saúde”. Em: PEIXOTO, M. (Org.). A saúde dos antigos. São Paulo: Loyola, 2009. DUSSEL, E.; MENDIETA, E.; BOHÓRQUEZ, C. (Ed.) El pensamiento filosófico latino-americano, del Caribe y "latino" [1300-2000]. Mexico: Siglo XXI, 2009.

GOMES, R. Crítica da razão tupiniquim. 12. ed. Curitiba: Criar, 2001.

LEITE, S. História da Companhia de Jesus no Brasil, VII. Belo Horizonte: Itatiaia, 2006.

MARGUTTI, P. História da filosofia do Brasil (1500-1822). São Paulo: Loyola, 2013.

MARQUES, L. A. A lógica da necessidade. Porto Alegre: Fi, 2018.

MARQUES, L. A. Philosophia brasiliensis. Porto Alegre: Fi, 2015.

NUNES, B. Ensaios filosóficos. Organização de V. S. Pinheiro. São Paulo: Martins Fontes, 2010.

REDMOND, W. B. Bibliography of the Philosophy in the Iberian Colonies of America. Netherlands: Martins Nijhoff; The Hague, 1972.

ROMERO, S. História da literatura brasileira. Tomo I. Organização de L. A. Barreto. Rio de Janeiro: Imago e Sergipe: UFS, 2001.

SILVEIRA, R. A. T. A brasileiríssima filosofia brasileira. Síntese, v. 43, n. 136, 2016. p. 261-278. 
STRAUSS, A. et al. The Oldest Case of Decapitation in the New World. In: Plosone. September 23, 2015. p. 1-31. Disponível em https://journals.plos.org/plosone/ article?id=10.1371/journal. pone.0137456. Acesso em: 25 mar. 2020.

VAINFAS, R. (Org.) Dicionário do Brasil Colonial. Rio de Janeiro: Objetiva, 2001.

VAZ, H. C. L. O problema da filosofia no Brasil. Síntese, v. 30, 1984. p. 11-25.

VITA, L. W. Panorama da filosofia no Brasil. Porto Alegre: Globo, 1969.

ZEA, L. La filosofía americana como filosofía sin más. 13. ed. México: Siglo XXI, 1989.

ZIMMERMANN, R. América Latina: o não-ser. Petrópolis: Vozes, 1987.

\section{Sobre o autor}

\section{Lúcio Álvaro Marques}

Doutor em Filosofia pela Pontifícia Universidade Católica do Rio Grande do Sul (PUCRS), com PósDoutorado em Filosofia Brasileira pela Universidade do Porto/Portugal (UPORTO). Professor do Departamento de Filosofia e Ciências Sociais (DFCIS) e no Programa de Pós-Graduação em Educação (PPGE) da Universidade Federal do Triângulo Mineiro (UFTM). Coordenador do Projeto de Pesquisa Políticas de ensino de filosofia no Brasil e membro do Laboratório de Filosofia e Ciências Sociais (LAFICS) de onde se originou, em parte, o presente artigo.

Recebido em: 08/04/2020.

Aprovado em: 12/06/2020.
Received: 08/04/2020.

Approved: 12/06/2020. 